\title{
KESESUAIAN PERTUMBUHAN TANAMAN SERBAGUNA JENGKOL, ALPUKAT, AREN, DADAP DURI (Archidendron paulciflorum, Persea America, Arenga pinnata, Erythrina variegata) BERDASARKAN PASOKAN BIBIT LOKAL GAYO LUES DALAM MENDUKUNG KEGIATAN REHABILITASI HUTAN DAN LAHAN DI BLOK DUA DESA SANGIR KECAMATAN DABUN GELANG KABUPATEN GAYO LUES
}

\author{
Fitness For Growth Of Versatile Plant Jengkol, Avocado, Aren, Dadap Duri (Archidendron \\ Paulciflorum, Persea America, Arenga Pinnata, Erythrina Variegata) Based On Gayo Lues Local \\ Growth Substance In Supporting Activities In Duacamil Human Resources \\ Ali Umer ${ }^{1}$, Martunis ${ }^{1}$, dan Ryan Moulana ${ }^{{ }^{*}}$ \\ Program Studi Kehutanan \\ ${ }^{1}$ Program Studi Kehutanan PSDKU USK Gayo Lues, Fakultas Pertanian, \\ Universitas Syiah Kuala \\ *Corresponding author: ryanmoulana@unsyiah.ac.id
}

\begin{abstract}
Abstrak. Setiap tahun kawasan hutan di Kabupaten Gayo Lues mengalami deforestasi dan degradasi yang disebabkan oleh aktivitas manusia. Salah satu upaya untuk menekan laju deforestasi tersebut dan mengembalikan kawasan hutan adalah dengan melakukan program Rehabilitasi Hutan dan Lahan (RHL). Data yang dikumpulkan berupa data primer melalui survei langsung ke lokasi dan data sekunder yang berasal dari instansi lain. Pengambilan data primer menggunakan metode Systematic Sampling with Random Start. Parameter penelitian yang diamati yaitu menganalisis pertumbuhan tanaman yang bersumber dari pasokan bibit lokal, persentase tumbuh tanaman pada blok dua dan persentase kondisi fisik jenis tanaman bibit lokal. Data dianalisis secara kuantitatif dan deskriptif. Persentase tumbuh tanaman dihitung dengan cara membandingkan jumlah tanaman yang ada dengan rencana jumlah tanaman yang seharusnya ada di dalam petak ukur. Hasil penelitian pada blok Dua Desa Sangir menyatakan bahwa bibit yang mememiliki persentase ratarata tertinggi terdapat pada jenis bibit jengkol $88 \%$ dan alpukat $85 \%$.
\end{abstract}

Kata Kunci: Rehabilitasi, hutan, bibit, pertumbuhan,

Abstract. Every year the forest area in Gayo Lues Regency experience deforestation and gedradation causesd by human activities. One of effort to reduce the rate of the forestation and restore forest areas in to carry out the Forest and Land Rehabilitation (FLR) program. The data collected in the form of primary data trhought direct surveys to location and secondary data from other agencies. Primary data collected using Systematic Sampling with Random Start method. The research parameter observed was to analyze plant growth sorce from local seed suplay. The percentage of plant growth in block two and the percentage of physical condition of local seedling plants spesies. Data were analyze quantitatively and descriptively. Percentage of plant growth is calculated by comparing thu number of existing plants with the planned number of plants that should be in the measuring plot. The result of the research in the block two Sangir Village stated that the seeds that had the highest average percent were $88 \%$ jengkol and $85 \%$ avocado seeds.

Keywords: rehabilitation, forest, seedling, growth

\section{PENDAHULUAN}

\subsection{Latar Belakang}

Gayo Lues merupakan kabupaten yang terletak di dataran tinggi Provinsi Aceh. Wilayah ini memiliki luas 554.991 hektar, terdiri hutan lindung, Taman Nasional Gunung Lueser, hingga hutan produksi. Setiap tahun keberadaan luas kawasan hutan di Kabupaten Gayo Lues semakin berkurang, hal ini disebabkan oleh aktivitas manusia melakukan kerusakan hutan yang menyebabkan terjadinya laju deforestasi dan degradasi hutan dan lahan. Yayasan Hutan Alam dan Lingkungan Aceh memperlihatkan data deforestasi berkurang 15.071 hektar sepanjang 2018, 
menurun dibandingkan 2017 yang mencapai 17.820 hektar, pada Kabupaten Gayo Lues mengalami laju deforestasi dan degradasi lahan sebesar 1.494 hektar. Rehabilitasi Hutan dan Lahan (RHL) merupakan suatu usaha memperbaiki, memulihkan kembali dan meningkatkan kondisi lahan yang rusak agar dapat berfungsi secara optimal baik sebagai unsur produksi, media pengatur tata air maupun sebagai unsur perlindungan alam dan lingkungannya. Keberhasilan pertumbuhan tanaman pada kegiatan ini tidak luput dari kualiatas bibit yang digunakan, kegiatan ini mengunakan pasokan bibit lokal Gayo Lues, bibit ini diharapkan dapat di aplikasikan pada kegiatan rehabilitasi hutan dan lahan.

\subsection{Perumusan Masalah}

Rumusan masalah pada penelitian ini yaitu:

Belum tersedianya data dan informasi yang pasti mengenai persentase tumbuh tanaman bibit lokal Gayo Lues pada blok dua di Desa Sangir.

\subsection{Tujuan Penelitian}

Adapun Tujuan dari penelitian ini adalah:

Untuk mengetahui tingkat kesesuian pertumbuhan tanaman serbaguna jengkol, alpukat, aren ,dadap duri (Archidendron paulciflorum, Persea America, Arenga pinnata, Erythrina variegata) yang bersumber dari pasokan bibit lokal dalam kegiatan Rehabilitasi Hutan dan Lahan pada blok dua di Desa Sangir.

\subsection{Manfaat Penelitian}

Manfaat dari penelitian ini adalah sebagai bahan informasi atau gambaran umum tentang tingkat pertumbuhan tanaman rehabilitasi hutan dan lahan berdasar sumber pasokan bibit lokal.

\section{METODOLOGI PENELITIAN}

\subsection{Tempat dan Waktu Penelitian}

Lokasi penelitian dilakukan di Desa Sangir, Kecamatan Dabun Gelang dan wilayah ini masuk ke dalam wilayah KPH V Kabupaten Gayo Lues. Waktu penelitian ini dilakukan dari bulan Juli sampai dengan Desember 2019.

\subsection{Alat dan Bahan}

Alat yang digunakan dalam penelitian ini yaitu GPS, tally sheet, alat tulis, alat hitung, meteran, kamera, dan laptop. Bahan yang digunakan dalam penelitian ini yaitu peta wilayah kerja, baterai GPS, dan perlengkapan P3K.

\subsection{Prosedur Penelitian}

Prosedur penelitian yang dilakukan yaitu dengan melakukan pengambilan data langsung di lokasi Rehabilitasi Hutan dan Lahan (RHL) sesuai dengan parameter yang telah ditentukan. Parameter penelitian tersebut yaitu: hanya menganalisis tingkat pertumbuhan bibit yang bersumber dari pasokan bibit lokal atau bibit yang sediakan pada lokasi kegiatan.

\subsection{Penentuan Petak Ukur}

Petak ukur adalah satuan sampling yang berupa bagian dari luasan sebuah tegakan dimana akan dilakukan pengukuran dan pengamatan. Jumlah tanaman perhektar dijumlahkan hasil dari catatan yang tanaman yang banyak ditemui dalam lokasi masing-masing persatuan Ha. Akumulasi tanaman per $\mathrm{Ha}$ berkesinambungan dengan Permenhut No.P.60/Menhut-11/2009 mengenai landasan nilai ketercapaian upaya hutan, ditetapkan jumlah tanaman yang ditanam pada jarak 
tanam maks $4 \mathrm{~m} \times 4 \mathrm{~m}$ hingga tanaman yang ada pada satu petak ukur lokasi tanam minimal 63 tanaman untuk pola tanam intensif.

\subsection{Parameter Penelitian}

Adapun parameter dari penelitian ini adalah:

- Mengamati kondisi fisik tanaman (sehat, kurang sehat, merana dan mati) pada jenis tanaman bibit lokal.

- Menganalisis persentase tingkat pertumbuhan tanaman yang bersumber dari pasokan bibit lokal (kondisi tanaman hidup dan tanaman mati).

\subsection{Analisis Data}

Data yang telah dikumpulkan lalu dianalisis secara kuantitatif dan deskriptif. Mengumpulkan jurnal dan sumber informasi lain yang mendukung penelitian.

\subsubsection{Persentase Tumbuh Tanaman}

Persentase tumbuh tanaman dapat di hitung menggunakan rumus berikut:

$$
\begin{aligned}
\mathrm{T} & =(\Sigma \mathrm{hi} / \Sigma \mathrm{Ni}) \times 100 \% \\
= & \frac{(\mathrm{h} 1+\mathrm{h} 2+\cdots \mathrm{hn})}{(\mathrm{N} 1+\mathrm{N} 2+\cdots \mathrm{Nn})} \times 100 \%
\end{aligned}
$$

Keterangan:

$$
\begin{array}{ll}
\mathrm{T} & =\text { persen (\%) tumbuh tanaman } \\
\mathrm{hi} & \text { = jumlah tanaman hidup (sehat/tidak sehat/merana) yang terdapat pada petak ukur ke - } \mathrm{i} \\
\mathrm{Ni} & =\text { jumlah tanaman yang semestinya hidup pada petak ukur ke }-\mathrm{i}
\end{array}
$$

\subsubsection{Persentase Kondisi Fisik Jenis Tanaman Bibit Lokal}

Nilai persentase kondisi fisik jenis tanaman ini ialah dengan mengklasifikasikan jenis tanaman yang digunakan dengan mengkategorikan kondisi fisik tanaman menjadi 4 yaitu, sehat, kurang sehat merana dan mati dari kedua sumber bibit lokal dan bibit dari luar. Hasil akhir dari analisa ini didapatkan dari hasil membandingkan jumlah kondisi tanaman dibagi jumlah total jenis tanaman dikali $100 \%$.

\section{HASIL DAN PEMBAHASAN}

\subsection{Pasokan bibit}

Pada kegiatan Rehabilitasi Hutan dan Lahan di Desa Sangir, Kecamatan Dabun Gelang, Kabuoaten Gayo Lues, pihak pelaksana telah menentukan beberapa jenis tanaman yang di tanama pada lokasi RHL, dan tanaman tersebut sepenuhnya berasal darai lokasi kegiatan RHL atau dapat disebut sebagai bibit tanaman lokal. Jenis tanaman yang berasal dari pembibitan lokal tersedia pada tabel 1 berikut:

Tabel 1. Sumber pemasokan Bibit Tanaman Pada Blok 02

No

Jenis bibit

Bibit Lokal

\footnotetext{
$1 \quad$ Alpukat (Persea america)

2 Jengkol (Archidendron pauciflorum)
} 
3 Aren (Arenga pinnata)

$4 \quad$ Dadap Duri (Erythrina variegata)

Sumber: Data Hasil Penelitan

Pada Tabel 2 dapat diketahui bahwa keempat jenis bibit tersebut merupakan bibit tanaman yang berasal dari lokasi RHL atau bibit lokal. Keempat jenis tersebut yaitu Alpukat, Jengkol, Aren dan Dadap duri. Hal ini dikarenakan bibit tersebut mudah untuk ditemukan di sekitar lokasi pembibitan dan ketersediaan bibit juga memadai.

\subsection{Persentase Kesehatan Tanaman (Sehat, Tidak Sehat, Merana dan Mati)}

Kegiatan Rehabilitasi Hutan dan Lahan yang dilakukan di di block Dua Desa Sangir Kecamatan Dabun Gelang Kabupaten Gayo Lues yaitu memeiliki oetak tanam sebanyak 8 buah. Pada pengamatan ini, peneliti mendata keempat tanaman tersebut dari keadaan fisik atau kesehatannya yang masuk dalam 4 kategori yaitu tanaman sehat, tanaman kurang sehat, tanaman merana dan tanaman mati. Informasi hasil pengamatan tersedia pada diagram berikut:

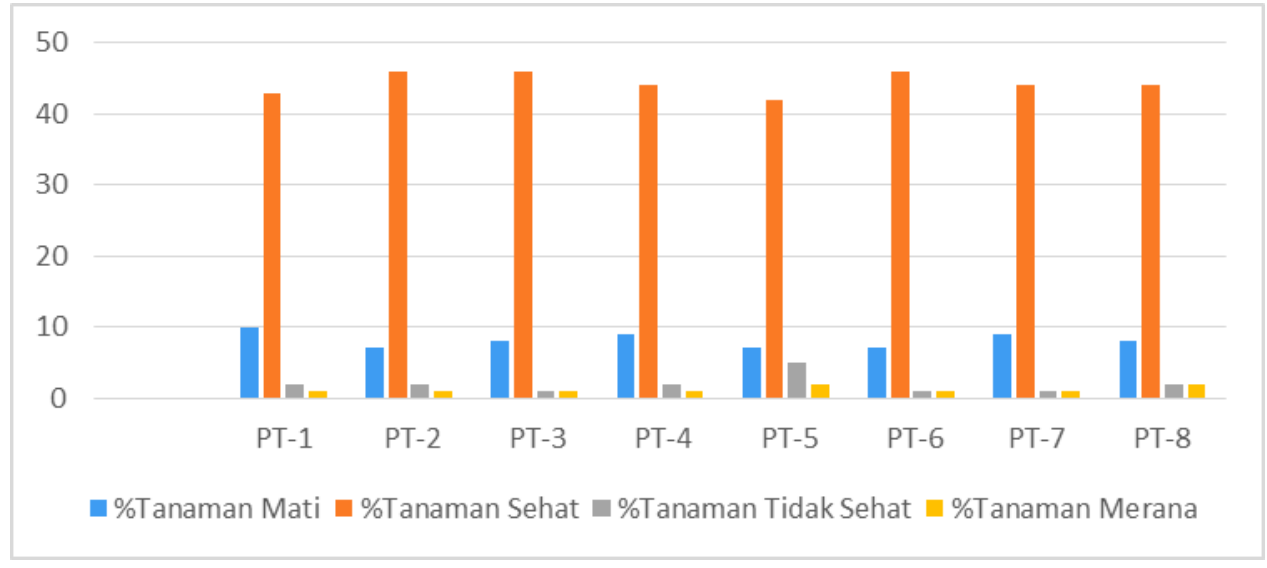

Gambar 1. Diagram Persentase Kesehatan Tanaman

Data grafik diatas menunjukkan bahwa jumlah tanaman yang sehat sangat jauh lebih banyak dibandingkan dengan tanaman yang mati. Pada diagram diatas menunjukkan bahawa petak tanam 2, 3 dan 6 memiliki persentase tanaman sehat tertinggi dengan masing-masing sebesar $46 \%$. Petak tanam dengan tingkat tanaman sehat tertinggi berikutnya terdapat pada petak tanam 4,7 dan 8 dengan masing-masing sebesar $44 \%$. Sedangkan petak tanam 1 sebesar $43 \%$ dan petak tanam 5 adalah persentase tanaman sehat terendah yaitu sebanyak $42 \%$.

Tingginya persentase tumbuh pada tanaman dipengaruhi dari baiknya kualitas bibit yang ditanam. Bibit yang ditanam merupakan bibit pilihan yang terlihat baik dari penampakan visualnya atau dapat dilihat secara langsung. Bibit yang ditanam di lokasi rehabilitasi hutan dan lahan memiliki kondisi fisik yang kokoh, bersih, dan berwarna hijau segar. Kondisi tanaman tersebut dipengaruhi dari adanya perlakuan baik di lokasi persemaian pada saat bibit mulai berkecambah hingga bibit siap tanam. Selama di lokasi persemaian, para petugas memberikan beberapa perlakuan terhadap tanaman, diantaranya adalah dengan rutin melakukan pengecekan terhadap kondisi tanaman, melakukan pengawasan dan pencegahan terhadap hama, serta memberikan pupuk dan penyiraman yang cukup terhadap tanaman. Salah satu faktor yang dapat mempengaruhi proses pertumbuhan tanaman adalah dari proses pemilihan benih. Memilih benih yang baik akan 
menghasilkan bibit yang baik pula. Bibit yang baik dan berkualitas dihasilkan dari benih yang telah melalui tahapan pemilihan yang meliputi kematangan benih dan ukuran benih (Powell, 2006).

Pratiwi at al., (2012) mengatakan bahwa tingkat persen tumbuh dapat dipengaruhi oleh antara lain kondisi dan cara pengangkutan bibit, serta cara penanaman dan pemupukan. Kandungan bahan organik dalam tanah juga menjadi faktor lain yang berperan dalam menentukan keberhasilan suatu tanaman. Hal ini dikarenakan bahan organik dapat meningkatkan kesuburan kimia, fisika maupun biologi tanah. Keberadaan tanaman yang tumbuh menunjukkan bahwa jenis-jenis yang sudah ada memiliki kemampuan berkompetisi untuk mempertahankan hidup dan tegakan yang ada di lahan kompensasi dalam kondisi cukup stabil (Kalima, 2007).

\subsection{Persentase Kondisi Tanaman Bibit Lokal}

Pada penelitian tersebut, keempat tanaman diamati kondisi tanaman yaitu sehat, mati, kurang sehat dan merana. Pada pengamatan berikutnya pengamatan meliputi persentase pengelompokan tanaman yaitu hidup dan tanaman mati. Informasi mengenai status tanaman tersedia pada gambar diagram berikut:

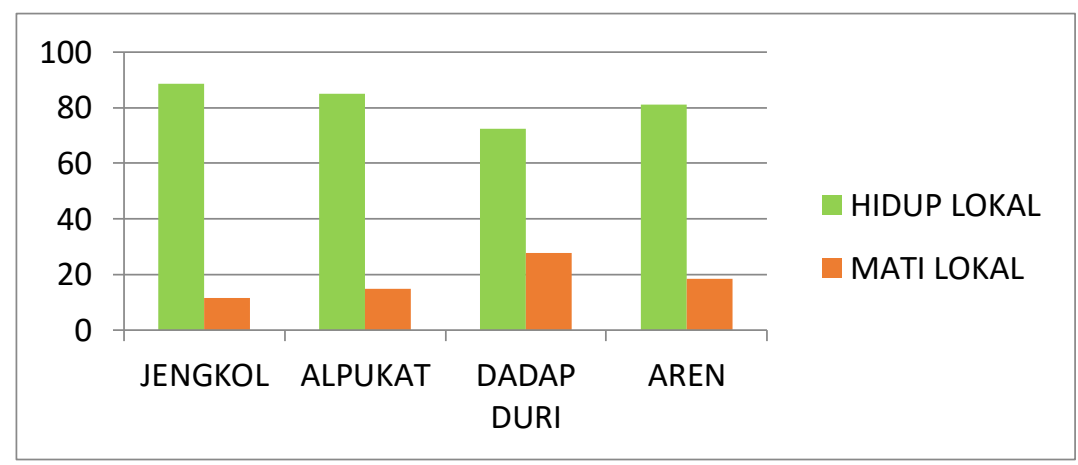

Gambar 2. Persentase Rata-Rata Kondisi Tanaman Lokal dan Luar

Berdasarkan data grafik diatas menunjukkan bahwa status tumbuh pada keempat tanaman jauh lebih tingi dibandingkan dengan status tanaman yang mati. Grafik tersebut menunjukkan bahwa dari keempat tanaman tersebut, jengkol merupakan tanaman yang paling banyak hidup yaitu sebesar $88 \%$, kemudian alpokat dengan nilai sebesar $85 \%$, aren sebesar $81 \%$ dan dadap duri sebesar $72 \%$. Tingginya persentase hidup pada jengkol dan alpokat dapat dipengaruhi karena tempat pembibitan kedua tanaman tersebut merupakan lokasi yang sangat dekat dengan lokasi penanaman. Lokasi pembibitan yang sangat dekat dengan lokasi penanaman menjadikan kedua tanaman tersebut sangat cepat dalam proses pendistribusian dan hal ini sangat berpengaruh pada kualitas kesehatan bibit pada saat penananaman. Bibit yang masih sehat dan segar merupakan salah satu factor yang membuat persentase tumbuh pada tanaman lebih tinggi.

Jenis tanaman aren dan dadap duri mempunyai tingkat pertumbuhan hidup ketiga dan keempat, hal ini dapat disebabkan karena lokasi pembibitan yang lebih jauh mengakibatkan tekakanan terhadap bibit pada saat proses pendistribusian ke lokasi tanam. Dari grafik diatas juga dapat diketahui bahwa keempat jenis tanaman tersebut juga terdapat beberapa tanaman yang mati pada lokasi penananaman, namun status hidup pada tanaman jauh lebih tinggi. Rata-rata jenis tanaman bibit lokal memiliki jumlah persentase kondisdisi tanaman sehat yang tinggi, hal ini dikarenakan tanaman bersumber dari lokasi yang telah berdaptasi terhadap lingkungan setempat, khususnya adaptasi terhadap iklim. Kematian yang terjadi pada tanaman yang di tanam pada lokasi lain mempunyai beberapa factor penyebab, diantaranya adalah tingkat stress pada tanaman dan kerusakan pada akar tanaman tersebut. Keadaan stress pada tanaman dapat dilihat dari kondisi 
tanaman seperti layu, kering dan terdapa kerusakan pada akar maupun pada pucuk daun yang dpat diakibatkan dari proses pengangkutan yang jauh.

Nirawati et al. (2013) menyatakan bahwa persentase hidup yang rendah tersebut bisa dipengaruhi oleh beberapa faktor antara lain : tata waktu pelaksanaan setiap tahapan kegiatannya tidak berkesinam-bungan sehingga diduga menyebabkan kondisi/keadaan bibit yang ditanam sudah dalam keadaan yang rusak karena melihat kondisi lokasi yang sulit dijangkau dan keadaan tanah yang berbatu dengan kedalaman $<25 \mathrm{~cm}$, sehingga untuk dapat hidup maksimal sangat sulit, penanaman yang tidak tepat musim tanam yang baik karena terlambatnya anggaran dan pemeliharan lanjutan. Kerusakan akar pada bibit akan membuat tingginya persentase kematian pada bibit setelah di tanam di lokasi. Sedangkan menurut Supriyadi dan Valli (1988) menyatakan bahwa kerusakan pada akar tanaman menyebabkan terjadinya infeksi jamur yang menggangu pertumbuhan tanaman bahkan menyebabkan kematian pada tanaman.

Dari data dan informasi diatas menunjukkan bahwa pada penyediaan bibit tanaman dalam kegiatan rahabilitasi dan lahan guna mendapatkan tingkat hidup yang tinggi pada tanaman adalah dengan menyediakan persemaian yang dekat dengan lokasi tanaman. Terkhusus pada tanaman aren diketahui bahwa tanaman tersebut merupakan spesies yang di alam keberadaannya banyak dijumpai di dekat sumber air, namun menurut Sunanto (1992), tanaman aren sesungguhnya tidak membutuhkan kondisi tanah yang khusus sehingga dapat tumbuh pada tanah-tanah liat, berlumur, dan berpasir.

\section{IV.SIMPULAN DAN SARAN}

\subsection{Simpulan}

Berdasarkan penelitian yang telah dilakukan dapat disimpulkan bahwa dari keempat jenis tanaman yang bersumber dari lokasi Rhl atau bibit lokal memeiliki nilai persentase tumbuh yang tinggi. Nilai persentase tumbuh yang tertinggi terdapat pada jenis tanaman jengkol yaitu sebesar $88 \%$, kemudian alpukat $85 \%$, aren $81 \%$ dan yang terakhir yaitu dadap duri dengan persentase nilai sebesar $72 \%$.

\subsection{Saran}

1. Bagi pelaksana fisik, agar kiranya pengadaan bibit dilakukan dengan cara membibitkan bibit di sekitar lokasi (lokal) penanaman untuk mengurangi risiko rendahnya persentase tumbuh tanaman.

2. Bagi akademisi, penelitian lanjutan mengenai tahapan kegiatan RHL ataupun dengan mengambil parameter penelitian lain sangat dianjurkan, agar diperoleh hasil data time series ataupun hasil evaluasi kegiatan RHL yang lebih lengkap.

\section{DAFTAR PUSTAKA}

Peraturan Menteri Kehutanan. 2009. Tentang Pedoman Penilaian Keberhasilan Reklamasi Hutan. Kementerian Kehutanan. Jakarta.

Rahmadi, R. 2019. Hutan Aceh Rusak. Tiga Masalah Besar ini Harus diselesaikan. Tersedia dalam: https://www.mongabay.co.id/2019/01/24/hutan-aceh-rusak-tiga-masalah-besar-ini-harusdiselesaikan/

Supriyadi, G. dan Valli, I. 1988. Manual persemaiaan ATA-267. Balai Teknologi Reboisasi (BTR) Banjarbaru, Kalimantan selatan. 
Nirawati., Baharuddin.N, Beta.P., 2013. Evaluasi Keberhasilan Pertumbuhan Tanaman Pada Kegiatan Rehabilitasi Hutan Dan Lahan (GNRHL) Di Taman Nasional Bantimurung Bulusaraung (Studi Kegiatan GNRHL Tahun 2003-2007). J. Sains dan Teknologi, Agustus 2013, Vol.13 No.2 : $175-183$

Powell, A.A. 2006. Seed vigour and its assessment. p. 603-636. In A.S. Basra. (Ed.). Handbook of Seed Science and Technology. The Haworth Press Inc. New York.

Pratiwi, Santoso, E. dan Turjaman, M. 2012. Penentuan Dosis Bahan Pembenah Ameliorant Untuk Perbaikan Tanah dari Tailing Pasir Kuarsa Sebagai Media Tumbuh Tanaman Hutan. Jurnal Penelitian Hutan dan Konservasi Alam9(2): 163-174

Kalima, T. 2007. KeragamanJenis danPopulasi Flora PohondiHutanLindung GunungSlamet, Baturaden, Jawa Tengah. Jurnal Penelitian Hutan dan Konservasi Alam4(2):151-160. 